\title{
Sagittal alignment of Lumbo-Sacral Spine in asymptomatic adults of Jammu province
}

\author{
Authors \\ Dr Tanveer Ahmed Bhat ${ }^{*}$, Dr Imtiyaz Ahmad Beigh², Dr John Mohd ${ }^{3}$ \\ ${ }^{1,2,3}$ Post graduate III yr, Deptt of Orthopedics GMC Jammu \\ *Corresponding Author \\ Dr Tanveer Ahmed Bhat \\ Post graduate III yr, Deptt of Orthopedics GMC Jammu, India
}

\begin{abstract}
Introduction: Alignment of the lumbosacral spine has an important impact on the dynamics of many spine and hip pathologies. The aim of our study was to assess the normal sacropelvic parameters and their correlation in asymptomatic Indian adults in relation to variations in sex and age.
\end{abstract}

Material and Methods: A group of 250 Volunteers were selected from general population with age ranging from 20-45 years. Radiography work was performed by a single radiographer to avoid bias. Left lateral radiograph was taken exposing C7 to S1 and both the hips while the volunteer was made to stand with a long $30 \times 90 \mathrm{~cm}$ cassette placed at $230 \mathrm{~cm}$ from the $X$-ray tube

Results: The average PI, PT, LL, SVA, and SS values were average 48.14 $\pm 10.40,10.10 \pm 6.10,55.36 \pm 10.08$, $16.98 \pm 9.54$, and $37.38 \pm 8.98$ respectively. No statistically significant difference was observed in statistical values with regards to sex. Our study showed that PI has significant positive correlations with SS, LL and $P T$, and also affects LL. SS have significant positive correlation with LL.

Conclusion: The current results broaden our understanding of normal sagittal spino-pelvic alignment and also serve as a basis for realignment strategies in adult population of Jammu region.

Keywords: Pelvic Incidence (PI), Lumbosacral Parameters, Lumbar Lordosis (LL), Thoracic Kyphosis (TK) Pelvic Tilt (PT), Sagittal Vertical Axis (SVA).

\section{Introduction}

Sagittal balance is maintained by lumbar lordosis and thoracic kyphosis contributing to the erect posture of humans. Utility of the sagittal plane contour in the function of the spine and in its various pathological diseases is a subject of increasing debate ${ }^{(1-3)}$. Recently, the number of spinal deformities treated surgically has stressed upon the importance of assessing spine contours in various planes ${ }^{(4,6,7)}$. To maintain sagittal balance lumbar lordosis plays a vital role ${ }^{(4)}$. Flat- back deformity arising after spinal surgeries due to reduced lumbar lordosis has a negative impact. Therefore, it is significant to evaluate the increase or decrease in lordosis and to determine the normal limits of the lumbar lordosis angle (LL). Presently there is no standardized technique for measuring the LL, and the variation in the selection of the upper and lower vertebrae which is used to measure lumbar lordosis is responsible for the variation in the lordosis range. 
Proper sagittal alignment is vital not only for the maintenance of a balanced standing posture but also to reduce the pain component of the quality of life ${ }^{(8)}$. Understanding these parameters with respect to racial and regional differences is very important ${ }^{(9-11)}$. Their importance also lies in better surgical planning and fixation of the spine.

The study was conducted to evaluate the normal sacropelvic parameters and curvatures of the spine and their correlation in asymptomatic Indian adults in relation to variations in sex and age.

\section{Material and Methods}

A prospective cohort of 250 normal asymptomatic adults who attended the outpatient department of tertiary care hospital government medical college Jammu from May 2017 to May 2018 with age between 20 and 45 years, no complaints related to spine and the ones who provided informed consent were included in the study after obtaining clearance from the Institute's ethical committee. Volunteers with any radiographic abnormality detected prior to or during the study, background of any spinal surgery or any contra-indication to radiation like pregnancy etc were excluded. Subjects included 145 men and 105 women with an average age of $33.46 \pm 7.31$ years. Subjects were made to stand and left lateral radiograph exposing C7 to $\mathrm{S} 1$ and both the hips with a long $30 \times 90 \mathrm{~cm}$ cassette placed at $230 \mathrm{~cm}$ from the X-ray tube was taken and this whole process was done by single radiographer avoiding bias. Subjects were instructed to stand in a comfortable position like hips and knees fully extended and upper limbs raised horizontally forward at $45^{\circ}$ of flexion at shoulder resting on two arm supports. The X-ray beam was centered on the $12^{\text {th }}$ thoracic vertebrae and X-ray was taken during inspiration. The complete axial skeleton extending from external auditory ducts above to superior third of femurs below was visualised. After marking of $\mathrm{X}$ ray films, the following radiographic parameters were measured by two observers independently on different days:1) sagittal vertical axis (SVA), defined as the horizontal distance between the 2) lumbar lordotic angle (LL), the angle from the upper endplate of L1 to the upper end plate of S1; 3) sacral slope (SS), the angle between the superior endplate of S1 and a horizontal axis; 4) pelvic tilt (PT), the angle between the line connecting the midpoint of the sacral plate to the axis of the femoral heads and the vertical axis; and 5) pelvic incidence (PI), the angle between the perpendicular to the sacral plate at its midpoint and the line connecting the point to the middle axis of the femoral heads (Fig. 1 and 2). An unpaired $t$-test was used to analyze the differences in the spinal and pelvic parameters between men and women. The correlations between the variables of spino- pelvic parameters were examined using the Spearman's rank correlation coefficient. $p$-values $<0.05$ were considered as statistically significant.

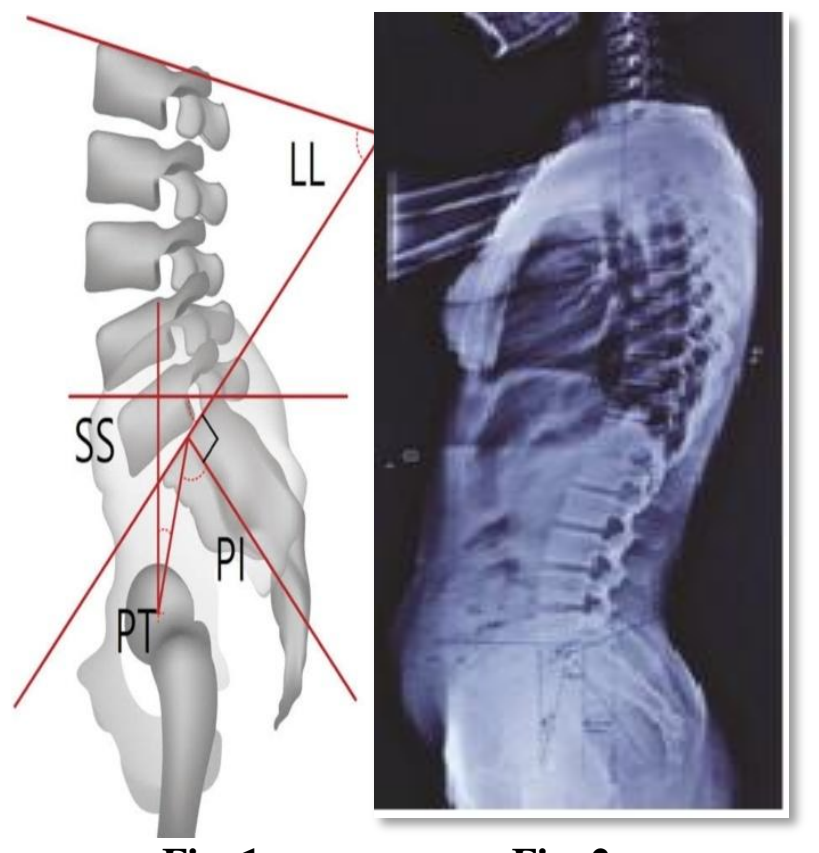

Fig. 1

Fig. 2

\section{Results}

The mean values of SVA, LL, SS, PT, and PI were $16.98 \pm 9.54 \mathrm{~mm}, 55.36 \pm 10.08^{\circ}, 37.38 \pm 8.98^{\circ}$, $10.10 \pm 6.10^{\circ}$ and $\quad 48.14 \pm 10.40^{\circ} \quad($ mean $\pm S D)$, respectively (table 1). Our results did not show any gender differences in pelvic morphologic angle or lumbar and pelvic alignment (LL, PI, PT,SS,SVA) (table 2). The correlation coefficients between PI and PT, SS, LL were $r=0.377$ 
$(\mathrm{p}=0.000), r=0.794(\mathrm{p}<0.001), r=0.567 \mathrm{p}=0.000)$, respectively (table 3 ). LL is closely related to the orientation of the pelvis, expressed by the SS, which is in turn affected by the PI. There is interdependence among the pelvic and spinal parameters PI, SS, and LL.

\begin{tabular}{|c|c|c|c|c|c|}
\hline \multicolumn{6}{|l|}{ Table-1 } \\
\hline Parameters & $\mathbf{N}$ & Min. & Max. & Mean & $\begin{array}{l}\text { Standard } \\
\text { deviation }\end{array}$ \\
\hline Age(yr) & 250 & 20 & 45 & 33.46 & 7.31 \\
\hline Body mass index $(\mathrm{kg} / \mathrm{m})$ & 250 & 16.73 & 27.06 & 22.85 & 1.75 \\
\hline Lumbar lordosis & 250 & 37 & 77 & 55.36 & 10.08 \\
\hline Sacral slope & 250 & 20 & 53 & 37.38 & 8.98 \\
\hline Pelvic incidence & 250 & 26 & 70 & 48.14 & 10.40 \\
\hline Pelvic tilt & 250 & 02 & 27 & 10.10 & 6.10 \\
\hline Sagittal vertical axis & 250 & 0.3 & 45 & 16.98 & 9.54 \\
\hline \multicolumn{6}{|l|}{ Table-2 } \\
\hline & Males $(n=145)$ & Females $(n=105)$ & \multicolumn{2}{|c|}{ T-value } & P value \\
\hline Lumbar lordosis & $55.36 \pm 10.08$ & $55.19 \pm 10.05$ & \multicolumn{2}{|c|}{0.78} & 0.436 , not sig. \\
\hline Pelvic incidence & $48.31 \pm 10.12$ & $47.73 \pm 9.47$ & \multicolumn{2}{|c|}{0.40} & 0.691 not sig \\
\hline Pelvic tilt & $9.99 \pm 6.41$ & $10.25 \pm 6.15$ & \multicolumn{2}{|c|}{0.28} & 0.780 not sig \\
\hline Sacral slope & $39.13 \pm 8.49$ & $37.96 \pm 8.24$ & \multicolumn{2}{|c|}{0.95} & 0.346 not sig \\
\hline SVA & $18.01 \pm 9.83$ & $16.83 \pm 9.59$ & \multicolumn{2}{|c|}{0.82} & 0.412 not sign \\
\hline \multicolumn{6}{|l|}{ Table-3 } \\
\hline Parameters & $\mathbf{L L}$ & SS & PI & PT & SVA \\
\hline LL & 1 & & & & \\
\hline SS & $\begin{array}{l}0.757 \\
0.000 \\
\end{array}$ & 1 & & & \\
\hline PI & $\begin{array}{l}0.567 \\
0.000\end{array}$ & $\begin{array}{l}0.794 \\
0.000\end{array}$ & 1 & & \\
\hline PT & $\begin{array}{c}-0.071 \\
0.318 \\
\end{array}$ & $\begin{array}{l}-0.009 \\
0.895 \\
\end{array}$ & $\begin{array}{l}0.377 \\
0.000\end{array}$ & 1 & \\
\hline SVA & $\begin{array}{l}-0.120 \\
0.090 \\
\end{array}$ & $\begin{array}{l}-0.045 \\
0.531 \\
\end{array}$ & $\begin{array}{c}-0.011 \\
0.882 \\
\end{array}$ & $\begin{array}{l}0.126 \\
0.076 \\
\end{array}$ & 1 \\
\hline
\end{tabular}

\section{Discussion}

It is of utmost importance to understand the spinal sagittal alignment for the management of spinal disorders. Failure to recognize malalignments in this plane can lead to spinal deformity and reduced quality of life ${ }^{(12)}$. It is well documented that sagittal spinal alignment is affected by $\operatorname{aging}^{(13)}$, spinal degeneration ${ }^{(14-16)}$, and hip joint disease $^{(17,18)}$, Offierski and MacNab ${ }^{(17)}$ described a causal link between arthritis of the hip joint and lumbar spondylosis, naming the mosiac of hip, low back pain, and sciatica as the "hip-spine syndrome". Recently, it has become clear that in order to analyze sagittal spinal alignment, the pelvic alignment should be included because of the large effects of individual pelvic morphologies ${ }^{(19)}$. There might be possible differences in spinal sagittal posture on the basis of age, gender and race differences.

Glattes et al in his study observed that patients who were slightly kyphotic at the proposed proximal junction compared with the average sagittal alignment in a normal population were not at a higher risk for developing a junctional kyphosis $^{(21)}$. Lafage et al has shown the importance of the spino-pelvic parameters and its importance in the treatment of patients with deformities and also their effects on osteotomies in these patients ${ }^{(20)}$. In order to correct the spinal deformities, surgeries should be aimed at a proper relationship between the sacropelvic parameters and the TK and LL, but its significant change can 
result in a less favorable clinical outcome. Only few studies in the literature have given the correlation between these parameters and the spinal curvatures, especially in asymptomatic subjects. It has been found that a strong correlation between the SS and the PI $(r=0.8)$, between the LL and SS $(r=0.86)$, between the PI and PT ( $r=0.66)$, and between the LL and PI, PT, and TK $(r=0.9)$ in their study. Our study showed that PI has significant positive correlations with SS, LL and PT, and also affects LL and also SS has significant positive correlation with LL. A positive correlation between the PI and SS indicates that subjects with a high PI tend to have higher values of SS. Similarly, a negative correlation between the SS and PT implies that as the SS increases, the PT decreases and vice versa to maintain a constant PI. PI correlations have shown that the relationship of the spinal anatomical portion is interdependent on its adjacent structures, particularly at the lumbopelvic level. However, PI had less effect on SVA; this is because the spinal alignment, including the thoracolumbar region, can compensate for the pelvic shape in order to maintain a smaller SVA. Our study thus helps to correlate these parameters, which will give its importance about the proper value of osteotomy angles needed to correct deformities and also define parameters in cases requiring long segment instrumentation and fusion. Thus, while planning for fixation and fusion in patients with a high PI, an adequate SS should be attained intraoperatively by maintaining adequate lordosis, failure of which will result in pelvic retroversion as a result of compensatory increase in the PT. However, because of aging or overload to the spine, that resulted in loss of spinal compensatory function would lead to a pathological spinal deformity. In order to achieve proper spino-pelvic alignment in the surgical planning for spinal deformity, the PI-LL value can be used to determine the amount of correction needed. In a recent study, excessive PI-LL mismatch has revealed an increased risk of spinal imbalance $^{(22)}$. Results of multiple regression analysis which were done in different studies also demonstrated that the SVA and PI-LL are related to age. There may be regional differences in sagittal spino-pelvic parameters as well. Therefore, there must be strong correlation among spino-pelvic parameters. This study conducted by us has certain limitations as the subjects selected were less in number. Thus, we are unable to extrapolate our results to be representative of standard values pertaining to our population setup. However, it is just a beginning and could be used as a guide in understanding regional normal values ofspino-pelvic parameters.

\section{Conclusion}

The results of this study could not only be helpful in understanding the basics of normal spinal sagittal alignment but also can go a longway in serving as a basis for realignment strategies in Jammu population

\section{References}

1. Okcu G, Yercan Y, Yorulmaz I et al. Radiographical analysis of the lumbar spine in the sagittal plan. Journal of Arthroplasty Arthroscopic Surgery 2000; 11: 145-50.

2. Cil A, Yazici M, Uzumcugil A et al. The evolution of sagittal segmental alignment of the spine during childhood. Spine 2005; 30: 93-100.

3. Kobayashi T, Atsuta Y, Matsuno T et al. A longitudinal study of congruent sagittal spinal alignment in an adult cohort. Spine 2004; 29: 671-6.

4. Kim JS, Oh SH, Kim SB et al. Wedge shape cage in posterior lumbar interbody fusion: Focusing on changes of lordotic curve. J Korean Neurosurg 2005; 38: 255258.

5. Wiggins GC, Ondra SL, Shaffrey CI. Management of iatrogenic flat-back syndrome. Neurosurg Focus 2003; 15: E8. 
6. Tuzun C, Yorulmaz I, Cindas A et al. Low back pain and posture. ClinRheumatol 1999; 18: 308-12.

7. Evcik D, Yucel A. Lumbar lordosis in acute and chronic low back pain patients. RheumatolInt 2003; 23: 163165.

8. Marty C, Boisaubert B, Descamps H et al. The sagittal anatomy of the sacrum among young adults, infants, and spondylolisthesis patients. European Spine J 2002; 11: $119-25$.

9. Kanemura T. Sagittal spino-pelvic alignment in an asymptomatic Japanese population. J Spine Res 2011; 2: 52-8.

10. Kim WJ, Kang JW, Yeom JS, et al. A comparative analysis of sagittal spinal balance in 100 asymptomatic young and old ages volunteers. J Korean Soc Spine Surg 2003; 10: 327-34.

11. Lee CS, Chung SS, Kang KC et al. Normal patterns of sagittal alignment of the spine in young adults radiological analysis in a Korean population. Spine (Phila pa 1976) 2011; 36: E1648-54.

12. Schwab F, Patel A, Ungar B et al. Adult spinal deformitypostoperative standing imbalance: how much can you tolerate? An overview of key parameters in assessing alignment and planning corrective surgery. Spine (Phila Pa 1976) 2010;35:2224-31.

13. Takemitsu $Y$, Harada $Y$, Iwahara $T$ et al. Lumbar degenerative kyphosis. Clinical, radiological and epidemiological studies. Spine (Phila Pa 1976) 1988; 13:1317-26.

14. Barrey C, Jund J, Noseda O. Sagittal bal ance of the pelvis-spine complex and lumbar degenerative diseases. A comparative study about 85 cases. Eur Spine J 2007; 16:1459-67.
15. Endo K, Suzuki H, Tanaka H et al. Sagittal spinal alignment in patients with lumbar disc herniation. Eur Spine J 2010; 19: 4358.

16. Vialle R, Ilharreborde B, Dauzac C et al. Is there a sagittal imbalance of the spine in isthmic spondylolisthesis? A correlation study. Eur Spine J 2007; 16:1641-9.

17. Offierski CM, MacNab I. Hip-spine syndrome. Spine (Phila Pa 1976) 1983; 8:316-21.

18. Yoshimoto H, Sato S, Masuda T, et al. Spino-pelvic alignment in patients with osteoarthrosis of the hip: a radiographic comparison to patients with low back pain. Spine (Phila Pa 1976) 2005; 30:1650-7.

19. Roussouly P, Nnadi C. Sagittal plane deformity: an overview of interpretation and management. Eur Spine J 2010; 19:1824-36.

20. Lafage V, Ames C, Schwab F, et al; International Spine Study Group.Changes in thoracic kyphosis negatively impact sagittal alignment after lumbar pedicle subtraction osteotomy: a comprehensive radiographic analysis. Spine (Phila $\mathrm{Pa}$ 1976) 2012;37:E180-E7

21. Glattes RC, Bridwell KH, Lenke LG et al. Proximal junctional kyphosis in adult spinal deformity following long instrumented posterior spinal fusion: incidence, outcomes, and risk factor analysis. Spine (Phila Pa 1976) 2005;30:1643-9

22. Schwab F, Ungar B, Blondel B, et al. Scoliosis Research Society-Schwab adult spinal deformity classification: a validation study. Spine (Phila Pa 1976). 2012; 37:107782. 